\title{
OPEN Amplify antimicrobial photo dynamic therapy efficacy with poly-beta-amino esters (PBAEs)
}

\author{
Stefano Perni, Emily C. Preedy \& Polina Prokopovich ${ }^{\bowtie}$
}

Light-activated antimicrobial agents (photosensitisers) are promising alternatives to antibiotics for the treatment of skin infections and wounds through antimicrobial photo dynamic therapy (aPDT); utilisation of this technique is still restricted by general low efficacy requiring long exposure time (in the order of tens of minutes) that make the treatment very resource intensive. We report for the first time the possibility of harvesting the cell penetrating properties of poly-beta-amino esters (PBAEs) in combination with toluidine blue $\mathrm{O}$ (TBO) to shorten aPDT exposure time. Candidates capable of inactivation rates 30 times quicker than pure TBO were discovered and further improvements through PBAE backbone optimisation could be foreseen. Efficacy of the complexes was PBAE-dependent on a combination of TBO uptake and a newly discovered and unexpected role of PBAEs on reactive species production. Chemometric approach of partial least square regression was employed to assess the critical PBAE properties involved in this newly observed phenomenon in order to elicit a possible mechanism. The superior antimicrobial performance of this new approach benefits from the use of well established, low-cost and safe dye (TBO) coupled with inexpensive, widely tested and biodegradable polymers also known to be safe. Moreover, no adverse cytotoxic effects of the PBAEs adjuvated TBO delivery have been observed on a skin cells in vitro model demonstrating the safety profile of this new technology.

Skin and soft-tissue infections (SSTIs) are some of the most common infections observed in ambulatory practice and hospitals; to further concern, their rate has increased in the last decades ${ }^{1}$. SSTI symptoms range from mild conditions, such as pyoderma, to serious life-threatening such as necrotizing fasciitis; besides the affected area (i.e. hands or legs) may lose functionality depending on the severity of the infection ${ }^{2}$. Clearly SSTI are simultaneously a threat to life and quality of life to patients and an economic burden to health care providers ${ }^{3,4}$; i.e. it has been estimated that every MRSA infection costs an extra $9000 £$ to the $\mathrm{NHS}^{5}$ while in the USA the total spent on the treatment of SSTIs tripled between 2000 and 2012, from $\$ 4.4$ to $\$ 13.8$ billion $^{6}$.

Antibiotics are the first line approach to treat SSTI, however their efficacy is rapidly decreasing in consequence of the growth of antibiotic resistance among pathogens. New antibiotics, such as oritavancin or delafloxacin, to treat SSTI, have emerged ${ }^{7,8}$; nonetheless it is expected that antibiotic resistance will outpace the development of new drug thus different antimicrobial treatment is urgently needed.

Photodynamic therapy is a local, repeatable non-invasive technique which might be an effective alternative to antibiotics for the treatment of local infections ${ }^{9}$, periodontitis ${ }^{10}$ and diabetic foot ulcer ${ }^{11,12}$. The mechanism of action of PDT derives from a light-induced excitation of a photosensitiser (PS) to singlet state and its conversion to triplet state, whose reactivity results in the generation of radicals and $\operatorname{ROS}^{13,14}$. These cell death inducing capabilities of ROS have found medical applications in cancer ${ }^{15}$ and infections (antimicrobial-PDT or aPDT) treatment ${ }^{14}$.

aPDT feasibility depends on the higher resistance of mammalian cells than pathogens to the oxidation induced by light activated compound ${ }^{16,17}$ and by biologically compatible light activated compounds PS ${ }^{13,14}$. Lethality mechanism of aPDT is multi-targets; hence it is not prone to induce further resistance ${ }^{14,18-20}$. A further benefit of aPDT is the possibility of inactivating not only viable cells but also virulence factors released by pathogens that can cause tissue damage after bacterial death ${ }^{21}$. This possibility makes aPDT stand alone in the variety 


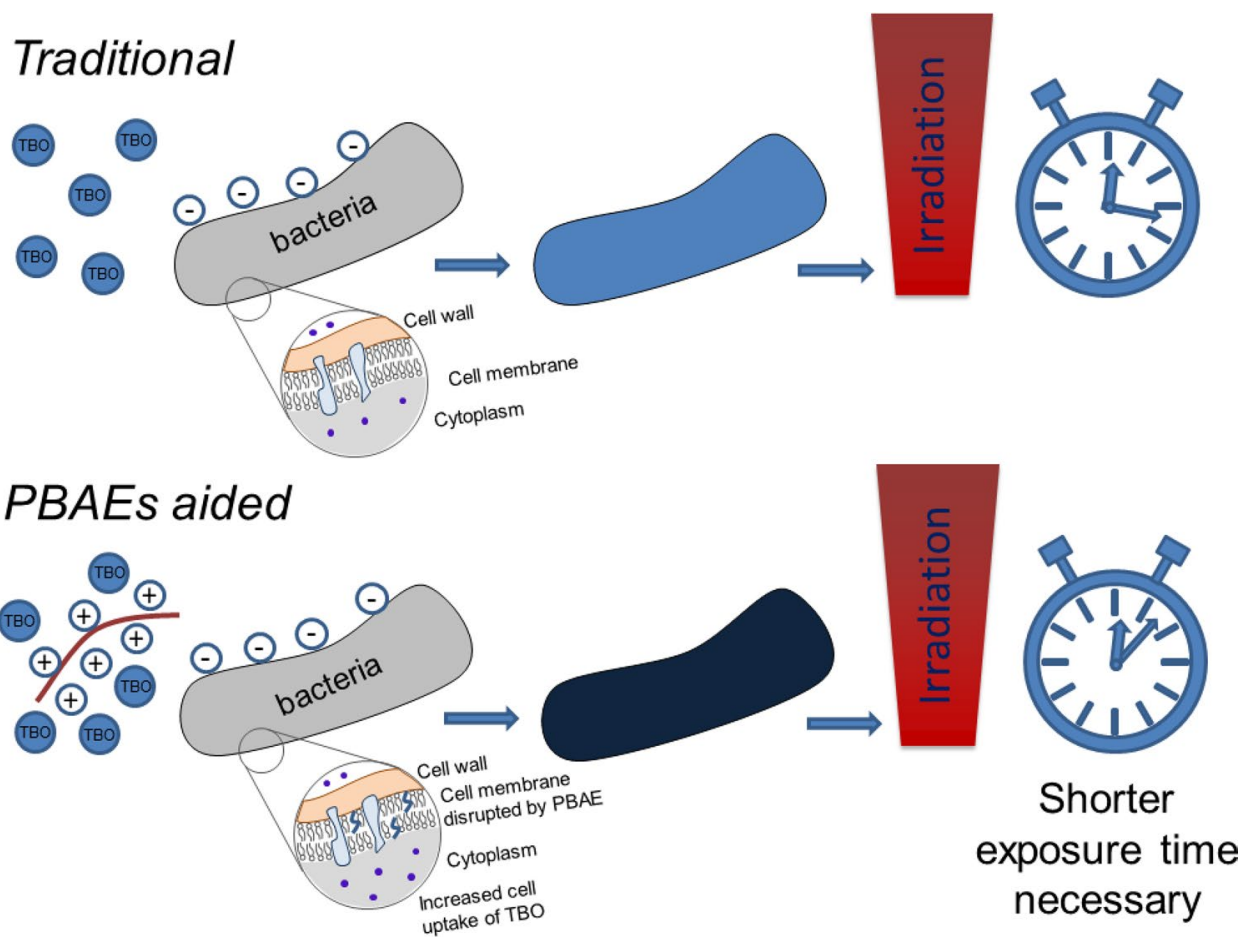

Figure 1. Schematic representation of the mechanism underpinning the enhancement of aPDT efficacy due to PBAE.

of antimicrobial techniques that are capable of only interacting with cells leaving virulence factors untouched. Clinical trials have also investigated aPDT for the treatment of skin infections ${ }^{22-25}$.

Despite the numerous mentioned benefits of aPDT, the necessary exposure time (in the order of $10-15 \mathrm{~min})^{26}$ is currently the main obstacle to its application in hospital settings as this limits the number of patients that can be treated per beds available. The challenge of reducing the irradiation time necessary to achieve aPDT satisfactory results has been addressed by developing delivery systems that augment PS uptake ${ }^{27,28}$ or designing novel PS that either exhibit selective affinity to bacterial cells over other tissue cells or are more potent ROS producers ${ }^{11,29-31}$. Despite the positive results, such advances are not yet sufficient in terms of efficacy or economically viable; consequently, new approaches are required in order to tackle the antibiotic resistance threat in a cost-effective way that maximises the return of health providers scarce resources.

Poly-beta-amino esters (PBAEs) were first described as biodegradable and biocompatible polymers with cell membrane penetrating characteristics that could be employed as gene transfer vectors in light of their positive charges and ability to form complexes with DNA molecules ${ }^{32}$. We hypothesised that PBAEs capabilities to actively deliver molecules inside cells could be exploited as adjuvant to microbial cell uptake of toluidine blue O (TBO) and demonstrated for the first time that PBAE-TBO complexes can have higher antimicrobial activity after laser exposure than the comparable amount of free dye on various pathogens representative of SSTI (Fig. 1). TBO was chosen in light of being one of the few light activated compounds already approved for clinical use ${ }^{14}$. We then investigated a library of PBAEs to judge whether optimisation was feasible and identified candidates capable of increasing inactivation rates to $>30$ times than those of pure TBO. This has the potential of providing the long-awaited break-through that could have clinical relevance in the treatment of SSTI. We also ascertained key PBAEs features that would allow further targeted development through data analytics algorithms. Finally, the effect on skin cells (keratinocytes and fibroblasts) was assessed in vitro to supplement the antimicrobial efficacy data of the technology with clear safety results.

\section{Materials and methods}

Synthesis of PBAEs. Acrylate-terminated poly( $\beta$-amino ester)s were synthesized by mixing 1,4-butandiole diacrylate, 1,6-hexanediol diacrylate or tetra(ethylene glycol) diacrylate with a range of amine monomers (Fig. 2) in dichloro-methane (DCM) with a acrylate excess ${ }^{33,34}$. The polymerisation, a Michael addition reaction (Fig. 3), was performed under stirring at $50{ }^{\circ} \mathrm{C}$ for $48 \mathrm{~h}$. PBAEs were precipitated through pouring the reaction mixture in about 10 times the volume of diethyl-ether under vigorous mixing; the solvent was then removed under vacuum.

Acrylate-terminated polymers of were dissolved in DCM at a concentration of $31.13 \% \mathrm{w} / \mathrm{w}$. A range of end capping agents (Fig. 2) were then added ${ }^{33,34}$. End-capped PBAEs were recovered through precipitation in diethyl-ether under vigorous mixing, the unreacted amines were removed centrifuging the suspension of PBAE in diethyl-ether/DCM for $2 \mathrm{~min}$ at $1155 \mathrm{~g}$. The supernatant was removed and the PBAEs washed twice with diethyl-ether. The end-capped PBAEs were then dried under vacuum. 


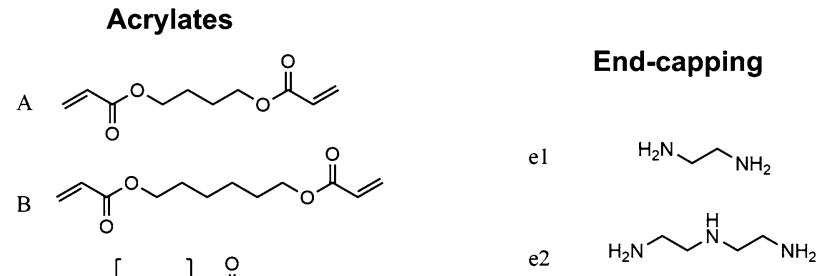

Amines

2

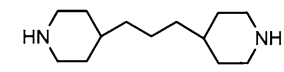

4

$5 \frown \mathrm{N} \frown \mathrm{NH}_{2}$

10

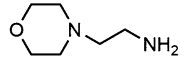

12

管 $\mathrm{NH}_{2}$

15<smiles>NC1CCCC1</smiles>

16<smiles>NCCCO</smiles>

17<smiles>NCCCn1ccnc1</smiles>

20

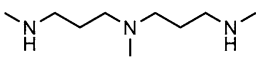

Figure 2. Structure and coding of constituents of PBAEs library used.

The PBAEs and derivatives obtained were coded through the constituents of the backbone using a capital letter to indicate the acrylate (e.g. A being 1,4-butanediol acrylate) and a number to indicate the amine as shown in Fig. 2; the further end-capping is describes by a number preceded by the letter e. For example, A2-e1 is the PBAE obtained from 1,4-butanediol diacrylate and 4,4'-Trimethylenedipiperidine then capped with ethylene-diamine.

PBAE characterization. Gel permeation chromatography (GPC) was employed to determine the molecular weight of each PBAE in the library. Samples were injected in a Shimadzu-LC-20Ai system equipped with a Superdex 75 10/300 GL column; the mobile phase was 100\% sodium acetate buffer $\mathrm{pH}=5$ at a constant flow of $1 \mathrm{~mL} / \mathrm{min}$. Number-averaged $(M n)$ and weight-averaged molecular weight $(M w)$ were determined against PEG standards. Molar masses were only apparent values due to the use of PEG standards and possible different hydrodynamic volumes of PEG standards and poly(beta-amino esters) of identical molar mass ${ }^{34}$.

Preparation of TBO-PBAEs complex. $10 \mathrm{mg}$ of TBO were dissolved in DCM (25 mL) along with $100 \mathrm{mg}$ of end-capped polymer; the solutions were immediately covered with aluminium foil and stirred for $24 \mathrm{~h}$ at room temperature. The PBAEs-TBO derivatives were recovered through precipitation in diethyl-ether under vigorous mixing, the unreacted molecules were removed centrifuging the suspension of PBAE in diethylether/DCM for $2 \mathrm{~min}$ at $1155 \mathrm{~g}$. The supernatant was removed and the PBAEs washed twice with a diethyl-ether/ DCM mixture 4:1. The end-capped PBAEs were then dried under vacuum and appeared viscous fluids at room temperature.

PBAE are known to form micelles when in aqueous fluids ${ }^{33,35}$, we hypothesized that the PBAEs-TBO complexes would be constituted by micelles containing TBO with PBAEs on the outer shell.

Antimicrobial protocol. The organisms used in this study were representatives of pathogens encountered in SSTI. Escherichia coli (NCTC10418), Staphylococcus epidermidis (ATCC12228), Pseudomonas aeruginosa (NCIMB10548), Methicillin Resistant Staphylococcus aureus (NCTC12493), Streptococcus pyogenes (ATCC19615) and Acinetobacter baumannii (NCIMB9214) were stored at $-80^{\circ} \mathrm{C}$. These organisms were subcultured, when needed, on Brain Heart Infusion (BHI) Agar overnight aerobically at $37^{\circ} \mathrm{C}$. The plates were then stored at $4{ }^{\circ} \mathrm{C}$ for no more than two weeks. Bacterial suspensions used for the experiments were grown in Brain Heart Infusion (BHI) broth after inoculation with a loopful of cells from a single colony on a BHI plate and incubated aerobically for $24 \mathrm{~h}$ at $37^{\circ} \mathrm{C}$ statically. These overnight cultures were then diluted 1 in 100 in PBS. The resulting bacterial suspension contained approximately $10^{6} \mathrm{CFU} / \mathrm{mL}$. Each cell suspension was used to disperse pure TBO to concentrations of $0.2 \mathrm{mg} / \mathrm{mL}$ or PBAEs-TBO derivatives to an equivalent TBO concentration.

$200 \mu \mathrm{L}$ aliquots of the resulting suspension were immediately poured in a GREINER 96 U-BOTTOM well plate. The well plate was then irradiated with a laser light $(633 \mathrm{~nm})$ using a $500 \mathrm{~mW}$ red laser (RRL635 nm-500 nm-1080060, Changchun New Industries Optoelectronics, China) for different time periods (between $10 \mathrm{~s}$ to $3 \mathrm{~min}$ ).

After exposure the bacterial cells $(\mathrm{L}+\mathrm{S}+)$ were counted through serial dilutions and plating on BHI Agar. Along this test, different experiments were performed including the testing of dark toxicity (labelled with L-S+), samples exposed uniquely to laser light $(\mathrm{L}+\mathrm{S}-$ ) or samples not exposed to either laser light or PBAE (L-S-). 
(a)

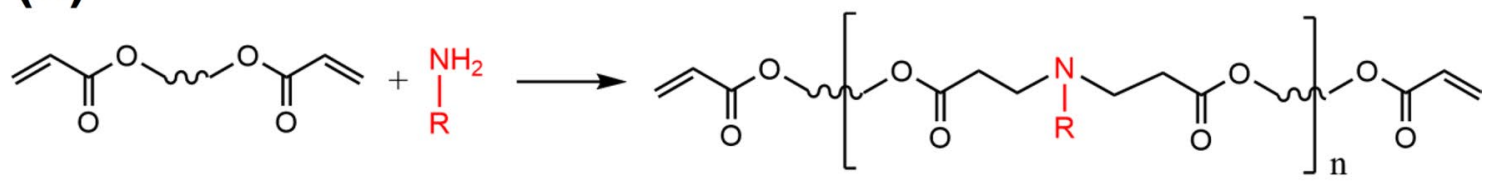<smiles>[R]NNC(=O)O[14CH2]OC(=O)C=[CH+]C(=O)C=C</smiles><smiles>[R]N(CCC(=O)ON([R])CCC(=O)OC(C)(C)COC(=O)C=C)NC(C)(C)OC(=O)C=C</smiles><smiles>[CH+]=CC(=O)OC(C)(C)COC(=O)OC(=O)OC(C)COC(=O)C=C</smiles>

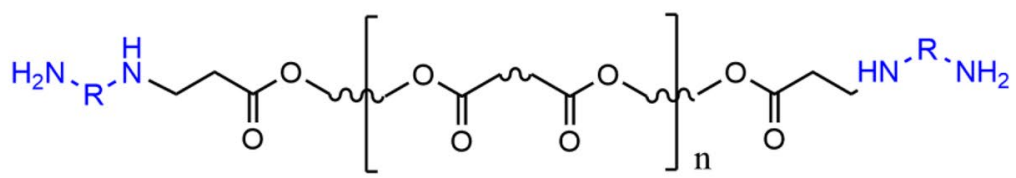

(b)

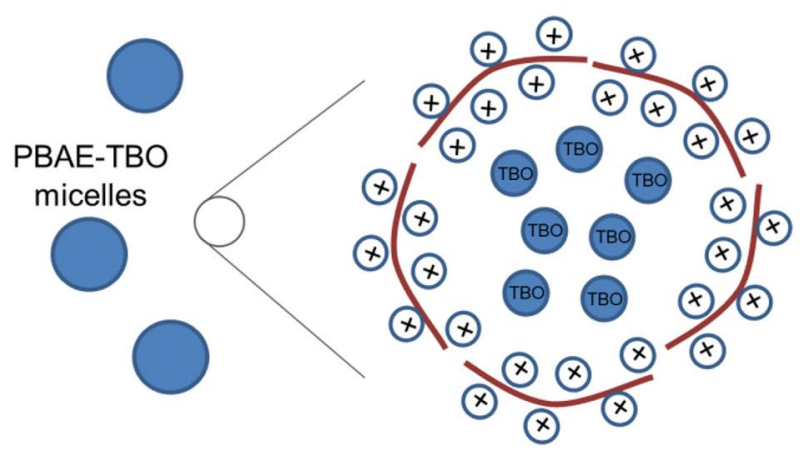

Figure 3. (a) PBAE structure and synthesis (b) PBAE-TBO micelles.

Through the experiments, all prepared samples, well plates and inoculated plates were immediately covered with aluminium foil to reduce biased measuring results due to exposure of any light besides the laser. All plates were incubated after the experiment for $24 \mathrm{~h}$ at $37^{\circ} \mathrm{C}$ prior to colony forming units counting. All experiments were performed on three independent cultures.

Spectroscopy. UV-Vis spectrum was determined using the Cary 60 UV-Vis Spectrophotometer (Agilent Technologies, United States).

Absorption of pure TBO and produced TBO-polymers complexes were measured using standard cuvettes. All samples were diluted in PBS to concentrations of equivalent to $20 \mu \mathrm{g} / \mathrm{mL}$ of pure TBO.

Reactive singlet oxygen species. The generation of reactive oxygen species (ROS) was assessed using a singlet oxygen Sensor Green reagent (SOSG) (Molecular Probes, Unites States). The SOSG was stored at $\leq-20^{\circ} \mathrm{C}$ and protected from light prior to use. The working solution was prepared with methanol to a final concentration of $5 \mathrm{mM}$. The prepared reagent was further diluted in methanol (1:100) before each experiment. Each sample was dispersed in PBS to a concentration equivalent to $0.2 \mathrm{mg} / \mathrm{mL}$ of pure TBO. $100 \mu \mathrm{L}$ of diluted sample, $100 \mu \mathrm{L}$ PBS and $20 \mu \mathrm{L}$ reagent were immediately poured in two adjoining wells of a GREINER 96 U-BOTTOM well 
plate. The irradiation of one well $(\mathrm{L}+)$ was in each case carried out for a period of $1 \mathrm{~min}$ with a $500 \mathrm{~mW}$ red laser (RRL-635 nm-500 nm-1080060, Changchun New Industries Optoelectronics, China); whilst the other well was covered with aluminium foil (L-). After exposure, ROS were determined using the FLUOstar OPTIMA (BMG Lab technologies, Germany).

TBO uptake in bacterial cells. $10 \mathrm{~mL}$ of fresh sterile BHI broth were inoculated with a loopful of cells from a single colony on a BHI plate and incubated aerobically for $24 \mathrm{~h}$ at $37^{\circ} \mathrm{C}$ statically. The bacterial suspension was then centrifuged with an Avanti J-20XP Centrifuge (Beckmann and Coulter, United States) for duration of $3 \mathrm{~min}$ at $2938 \mathrm{~g}$, afterwards the supernatant was disposed. After one wash and centrifuge with PBS, $1 \mathrm{~mL}$ of sample (equivalent concentration of pure $\mathrm{TBO}$ of $0.2 \mathrm{mg} / \mathrm{mL}$ ) was added to the precipitated cells. The resulting solution was vortexed and centrifuged after $3 \mathrm{~min}$ exposure. The exposure of samples to cells was limited to 3 min to ensure comparability to other experiments. After two more wash- and centrifugation cycles with PBS, the cells were dissolved in $1 \mathrm{~mL} 0.1 \mathrm{M} \mathrm{NaOH} / 1 \%$ sodium dodecyl sulphate (SDS) and incubated at $37^{\circ} \mathrm{C}$ for $24 \mathrm{~h}$ to lysate the cells.

The optical density of samples was measured at a $650 \mathrm{~nm}$ using a plate reader (Labtech LT5000MS) against a calibration curve prepared using the corresponding bacterial lysate.

Data analysis. Hieratical clustering (using Manhattan distance between PBAEs and complete distance between clusters) was performed R (ver 4.0) and the "stats" package ${ }^{36}$. Partial Least Square (PLS) regression analysis between PBAEs characteristics and ROS production ratio between PBAE-TBO complexes and pure TBO was carried out using R (ver 4.0) (36 $^{36}$ and the "plsdepot" package ${ }^{37}$.

The physical and chemical parameters of each PBAE constituents (amines and acrylates) were obtained from PubChem library (logP, TPSA, Complexity, Heavy Atom Count, Volume 3D, X_Steric Quadrupole 3D, Y_Steric Quadrupole 3D, Z_Steric Quadrupole 3D) while the parameters related to the basic repeated polymeric unit (amine + acrylate) were calculated through ChemDraw. These included molecular weight (MW), boiling point (BP); melting point (MP); critical volume (CV), Gibb's free energy (GFE), logP, solubility (logS), pKA, molar refractivity (CMR), heat of formation ( $\mathrm{HtF})$, TPSA and the ratio between the MW of amine and acrylate. TPSA (topological polar surface area) represents the total area of all polar atoms (mainly oxygen and nitrogen) including their affixed hydrogen atoms while $\log \mathrm{P}$ is the partition-coefficient between two immiscible phases at equilibrium which is proportional to hydrophobicity of the compound of interest ${ }^{34}$. Further experimentally determined properties of the PBAEs ( $\mathrm{Mw}, \mathrm{Mn}$ and zeta potential) were also added to the properties of PBAE included in the PLS regression.

The minimum number of PLS components to describe the role of different PBAEs chemical-physical properties on the ROS production was determined as the minimum number of PLS components that return at least $80 \%$ of the initial input data and an inflection in the scree plot representing the root mean squared error (RMSE) of the predictions vs. number of PLS components was $^{38,39}$.

In vitro safety assessment. Cells culture. Human keratinocytes cells (ATCC PCS-200-011) were grown in Dermal Cell Basal Medium supplemented with Keratinocyte Growth Kit (ATCC); whilst human dermal fibroblast cells were kindly supplied by Prof. Stephens ${ }^{40}$ from Cardiff University and grown in Minimum Essential Medium Eagle (MEM) supplemented with $10 \%$ heat-inactivated foetal bovine serum (FBS). Both media were supplemented with $1 \%$ penicillin-streptomycin (PS). Both cells lines were incubated at $37^{\circ} \mathrm{C}$ in a humidified air atmosphere with $5 \% \mathrm{CO}_{2}$; media were changed twice per week. 96 well plates were seed with $150 \mu \mathrm{L}$ containing 10,000 viable cells as determined through trypan blue staining and incubated for 5 days at $37^{\circ} \mathrm{C}$ in a humidified air atmosphere with $5 \% \mathrm{CO}_{2}$; media were changed after 2 days.

PDT exposure. Cells were washed three times with PBS and incubated with $100 \mu \mathrm{L}$ of either TBO $0.2 \mathrm{mg} / \mathrm{mL}$ or TBO-PBAE containing TBO $0.2 \mathrm{mg} / \mathrm{mL}$ After $2 \mathrm{~h}$, wells were washed once with $100 \mu \mathrm{L}$ of treatment media and maintained in this media thereafter. The well plate was then irradiated with a laser light (633 nm) using a 500 $\mathrm{mW}$ red laser (RRL-635 nm-500 nm-1080060, Changchun New Industries Optoelectronics, China) for 3 min.

Control experiments included testing of dark toxicity (labelled with $\mathrm{L}-\mathrm{S}+$ ), samples not exposed to TBO and uniquely to laser light $(\mathrm{L}+\mathrm{S}-)$ or samples not exposed to either laser light or PBAE (L-S-).

Cytotoxicity assay. $\quad 20 \mu \mathrm{L}$ of MTT stock solution $(5 \mathrm{mg} / \mathrm{mL})$ were added to each well and incubated in a humidified atmosphere at $37^{\circ} \mathrm{C}$ with $5 \% \mathrm{CO}_{2}$. After $4 \mathrm{~h}$, the supernatant was then removed and $100 \mu \mathrm{L}$ of dimethyl sulfoxide were added. The absorbance was measured by a spectrophotometer (Lab Tech LT5000MS) at $560 \mathrm{~nm}$; mitochondrial activity was normalised against cell exposed to fresh medium only.

$\mathrm{LDH}$ was quantified in the media (LDH released) and after adding the cell lysis solution (LDH total) according to manufacturer's protocols. Total and released $\mathrm{LDH}$ (indicated as $\mathrm{LDH}_{\text {total }}$ and $\mathrm{LDH}_{\text {released }}$ respectively) were determined as OD, at $490 \mathrm{~nm}$, after correcting for the reading from the negative control. Cell viability was calculated according to the following equation: ${ }^{41}$

$$
\text { viability }(\%)=\frac{L D H_{\text {total }}-L D H_{\text {released }}}{L D H_{\text {total }}} \times 100
$$

Statistical analysis. Differences among the different samples (L+S+, L-S+, L+S-, L-S-) in the MTT and $\mathrm{LDH}$ assays were tested through ANOVA with a significant level $\mathrm{p}=0.05$. 


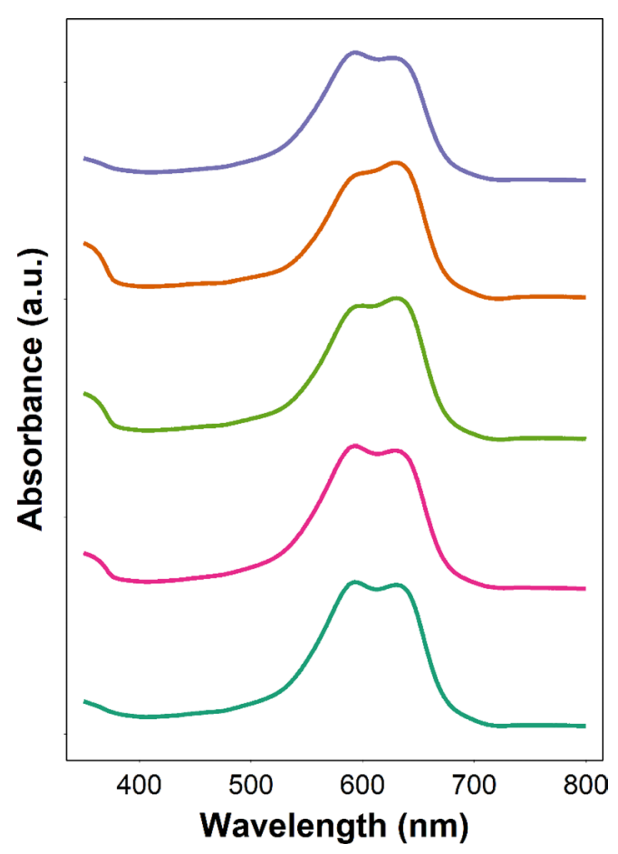

Figure 4. Example of UV spectra of TBO (dark green line) and PBAE-TBO (A3, orange line; B3, purple line; C3, pink line; and A5, light green line).

Multivariate analysis of variance (MANOVA) was carried out to test impact of the different end-capping agents on the antimicrobial activity, TBO cell up-take and ROS production of PBAE-TBO against pure TBO, using the Pillai test with a significant level $p=0.05$.

\section{Results}

UV spectra. UV-vis spectra of pure TBO showed a maximum of absorbance at about $633 \mathrm{~nm}$; spectra profiles did not vary when TBO was complexed with PBAE (Fig. 4).

Antimicrobial activity. In all six species tested (Fig. 5), viable bacteria decreased with the increase of irradiation time when in the presence of TBO $(\mathrm{L}+\mathrm{S}+)$; inactivation rates due to irradiation and TBO were higher for three Gram+ pathogens employed (S. epidermidis, MRSA and S. pyogenes) than the Gram- (P. aeruginosa, E. coli and A. baumannii).

In all cases, samples exposed to the polymer-TBO complex or to pure $\mathrm{TBO}$ without irradiation (L-) did not return any cell reduction over the time considered. In comparison, irradiated $(\mathrm{L}+)$ samples show tendencies of progressive reduction. The comparison with pure TBO showed an obvious improvement in the antimicrobial effect of laser exposure in all cases when the same amount of photosensitiser was employed along with A3-e1. Furthermore, when cells were exposed to laser light without the presence of photosensitiser $(\mathrm{L}+\mathrm{S}-$ ) did not reveal any antimicrobial activity. Furthermore, PBAE alone (without TBO) did not exhibit antimicrobial activity towards any of the pathogens tested either in the dark or after laser irradiation.

PBAE optimisation. The comparison of the efficacy of other PBAE as delivery system of TBO for antimicrobial PDT against an example of Gram- (E. coli) and an example of Gram+ (S. epidermidis) is shown in Fig. 6. Clustering of the PBAE synthesised revealed that main difference among polymers was the acrylate component with Poly(ethylene glycol) diacrylate (acrylate $\mathrm{C}$ ) forming a cluster more distant than 1,6-Hexanediol diacrylate (acrylate B) or 1,4-Butanediol diacrylate (acrylate A); the couples of amines 4,4'-Trimethylenedipiperidine (amine 2) and N,N-bis[(3-methylamino)propyl]methylamine (amine 20) along with 3-(dimethylamino)-1-propilamine (amine 5) and cyclopentylamine (amine 15) resulted in similar PBAE than any of the other amines.

Using similar amine and end-capping agent for the preparation of PBAE, 1,6-Hexanediol diacrylate (acrylate B) was usually more effective than 1,4-Butanediol diacrylate (acrylate A) with Poly(ethylene glycol) diacrylate (acrylate C) returning the worst antimicrobial activity of the three. Most of the PBAE-TBO complexes improve the antimicrobial activity compared to the same amount of pure TBO. PBAEs end-capped with e 2 had better antimicrobial activity that the respective counter-part end-capped with e1 $(p<0.05)$.

Cell uptake. All PBAE tested increased the uptake of TBO in both E. coli and S. epidermidis (Fig. 7), polymer exhibiting 1,6-Hexanediol diacrylate in their backbone performed better than those with 1,4-Butanediol diacrylate in most of the cases and the adjuvant effect of PBAE is remarkably greater in S. epidermidis than in E. coli. Poly(ethylene glycol) diacrylate generally did not enhance TBO cell uptake. PBAEs end-capped with e2 resulted in higher TBO cellular uptake that the respective counter-part end-capped with e1 $(p<0.05)$. 
(a)

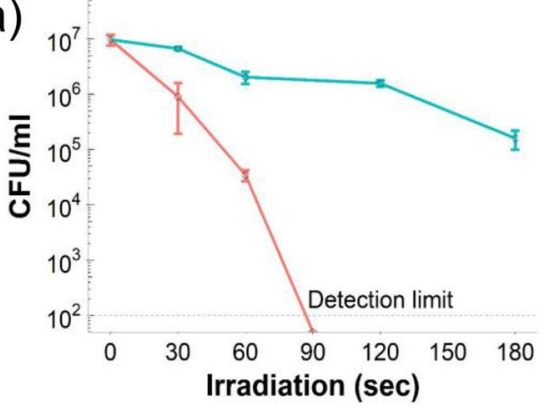

(b)

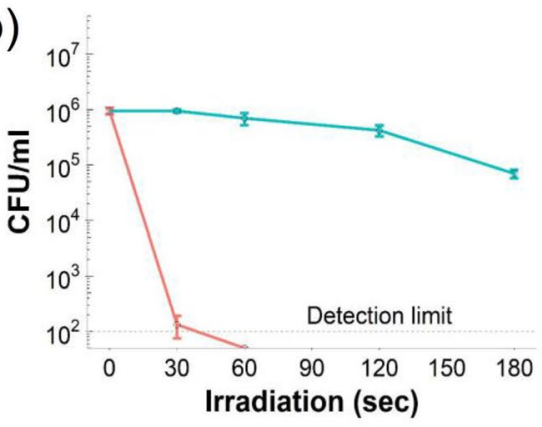

(c)

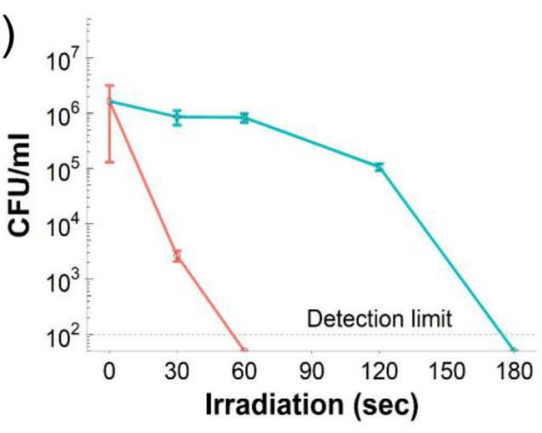

(d)

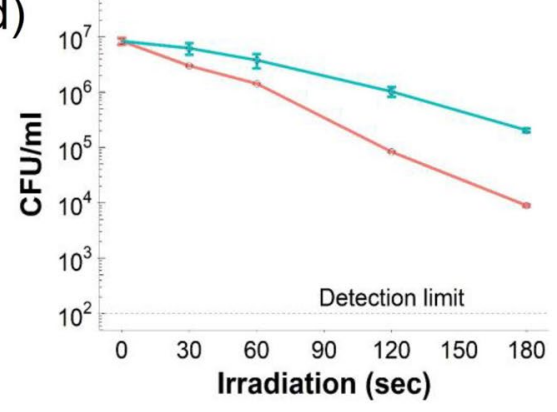

(e)

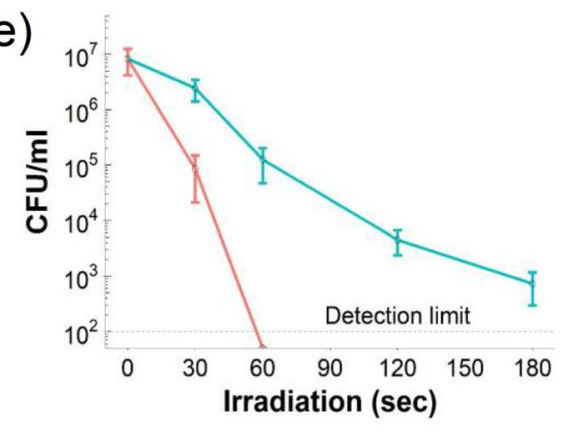

(f)

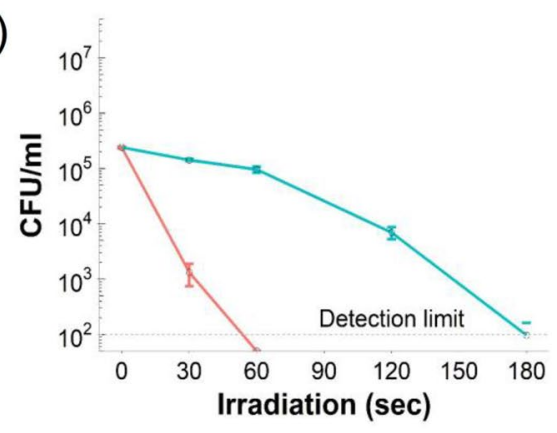

Figure 5. Antimicrobial activity of TBO (blue circles) and A3-e1-TBO (orange circles) against (a) E. coli, (b) $P$. aeruginosa, (c) A. baumannii, (d) MRSA, (e) S. epidermidis and (f) S. pyogenes (mean $\pm \mathrm{SD}, \mathrm{n}=3$ ).

Reactive oxygen species production. The amount of ROS generated by pure TBO only PBAE-TBO complexes is shown in Fig. 8 and reveals a strong dependence on the presence and structure of the PBAE. In most of the cases, ТВO complexes with polymers prepared with 1,6-Hexanediol diacrylate performed better than those prepared with 1,4-Butanediol diacrylate. TBO in combination with complexes of PBAEs end-capped with e2 resulted in higher ROS that the respective counter-part end-capped with e1 $(p<0.05)$.

No ROS were detected when only PBAE were exposed to laser light, hence PBAE are not photosensitisers. This demonstrate that PBAE do not only act in enhancing TBO uptake by cells but also have a direct role in the mechanism of radicals formation by PDT.

Antimicrobial activity of PBAE-TBO complexes on either S. epidermidis or E. coli was not solely depended on TBO uptake but was a combination of both uptake and ROS as not linear correlation was noticeable (Fig. 9).

PBAEs feature selection in ROS production. PLS model predictions of ROS production against the experimental data improved with increasing number of PLS components as represented by the increasing MRSE and $\mathrm{R}^{2}$ (Table S2 and Supplementary material). The scree plots exhibited an inflection at transition from 11 to 12 PLS components (Supplementary material); therefore 11 PLS components were chosen to describe the variation within this dataset of PBAE-TBO complexes. The experimental data of ROS production by PBAE-TBO synthesised were closely match by the predictions (Supplementary material); the residual did not reveal clear patterns (Supplementary material) and followed a normal distribution (Supplementary material).

For both end-capping agents, PBAE zeta potential was negatively correlated to the ROS production of the TBO-PBAE complexes after laser irradiation, on the contrary LogP and steric occupation (StericQuad3D) of the amine component of the polymer was positively correlated to ROS formation (Fig. 10). 
(a)

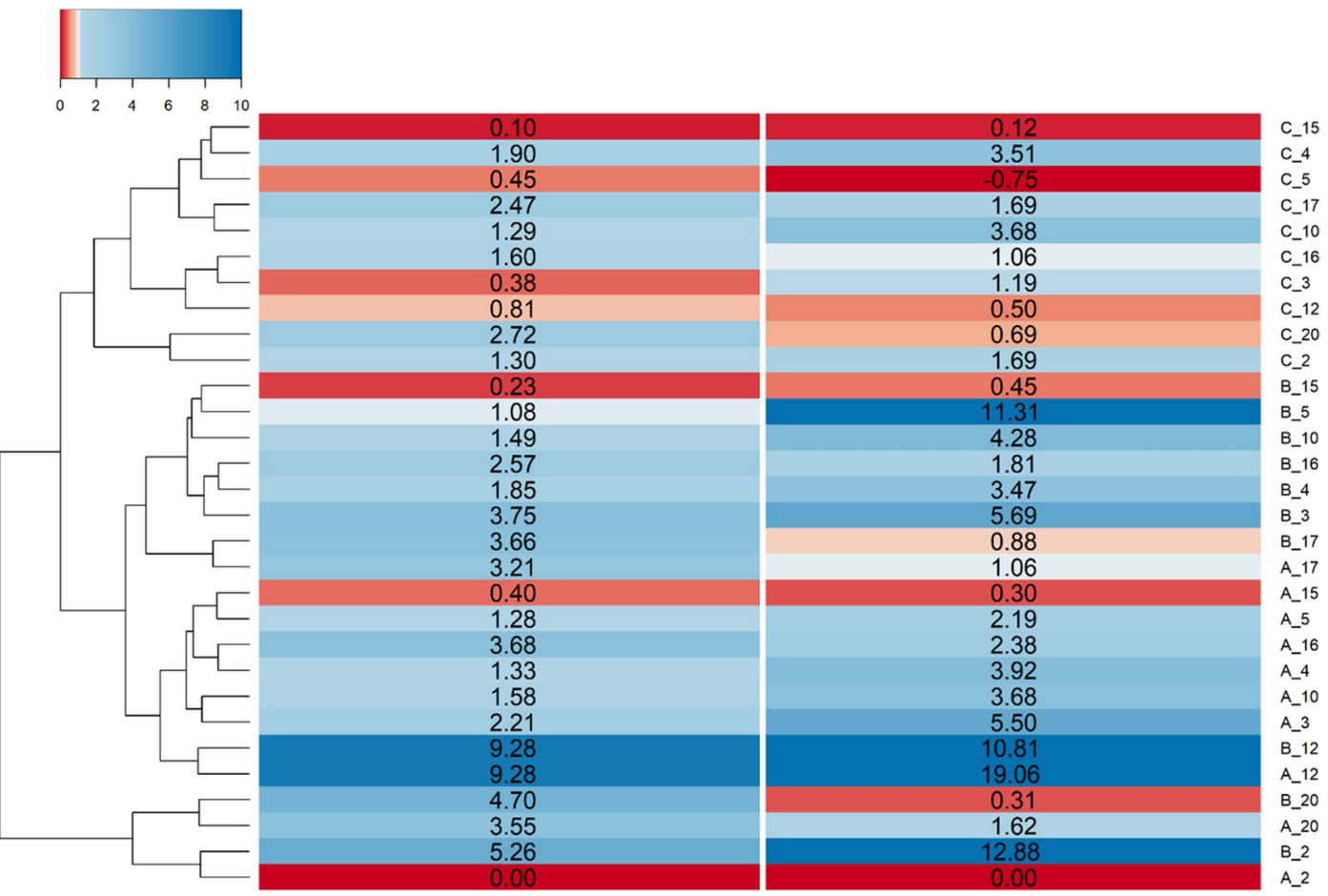

(b)
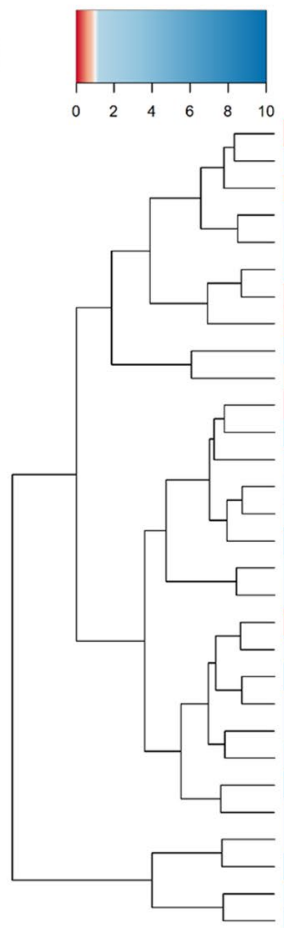

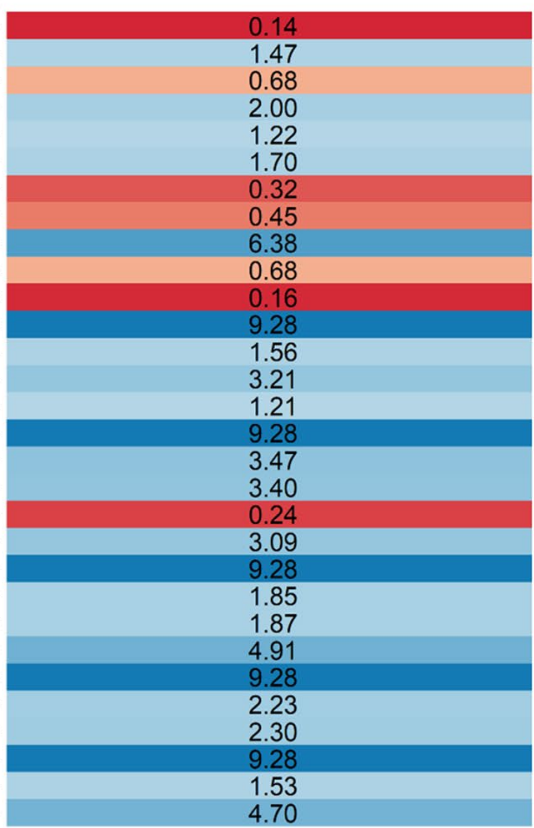

S. epidermidis

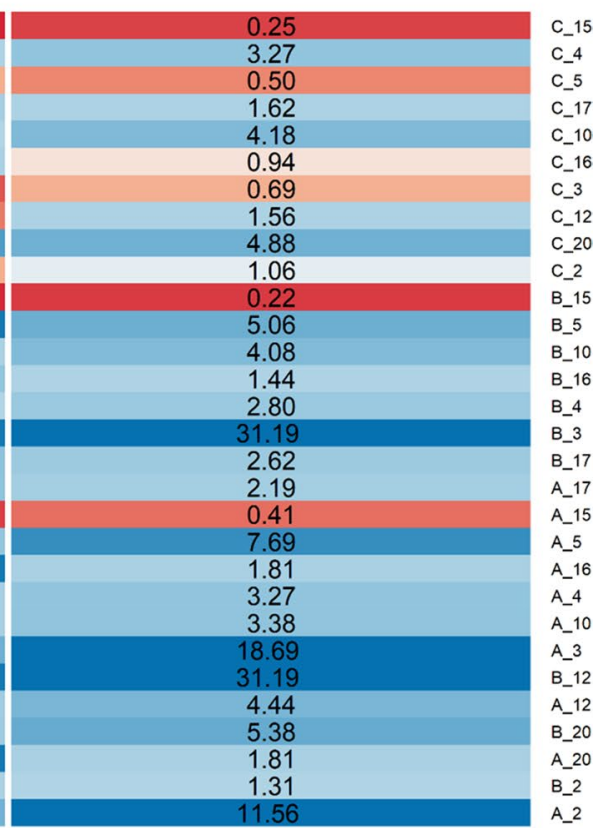

E. coli

Figure 6. $\log _{10}$ reduction of viable cells after $30 \mathrm{~s}$ laser exposure of E. coli and S. epidermidis comparted to pure TBO when exposed to different TBO-PBAEs end-capped with (a) e1 and (b) e2.

In vitro test on skin cells. Mitochondrial activity, estimated through MTT assay, and cell viability determined through LDH assay of both keratinocytes and fibroblasts were not impacted $(\mathrm{p}>0.05)$ by exposure to a selection of the TBO-PBAE prepared, additionally not dark toxicity was detected in either cell lines (Fig. 11). 
(a)
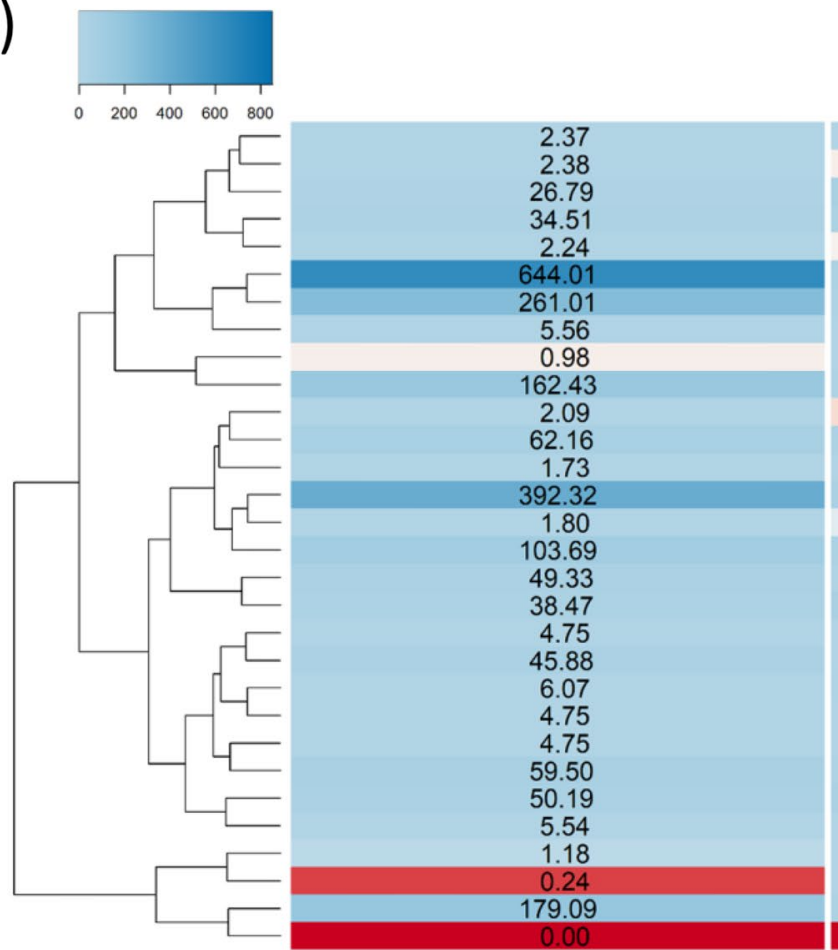

\begin{tabular}{|r|r|}
\hline 1.23 \\
0.98 \\
68.49 \\
43.12 \\
0.99 \\
42.35 \\
23.17 \\
3.66 \\
6.90 \\
18.39 \\
0.92 \\
28.09 \\
1.26 \\
51.87 \\
1.07 \\
28.17 \\
13.70 \\
53.57 \\
2.27 \\
6.69 \\
13.96 \\
2.27 \\
2.27 \\
25.13 \\
45.21 \\
4.47 \\
5.76 \\
2.99 \\
32.79 \\
0.00 \\
\end{tabular}

C_15

C_4

C_5

C_17

C_10

C_3

C_12

C_2

B_15

B_5

B_10

B_16

(b)

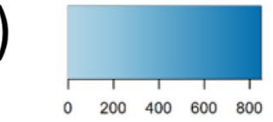

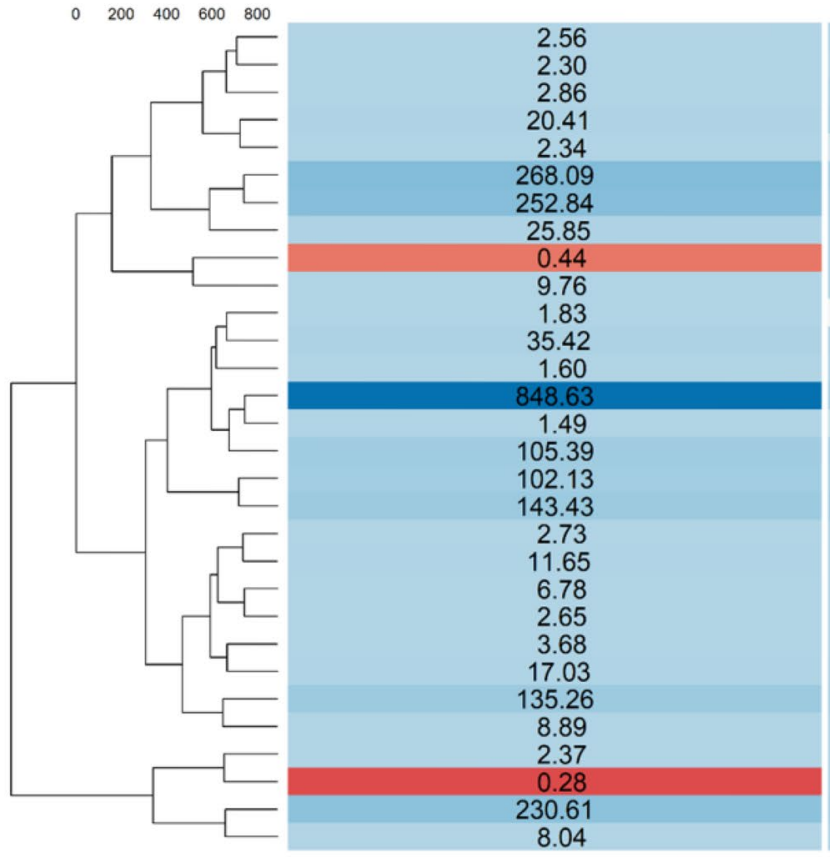

S. epidermidis

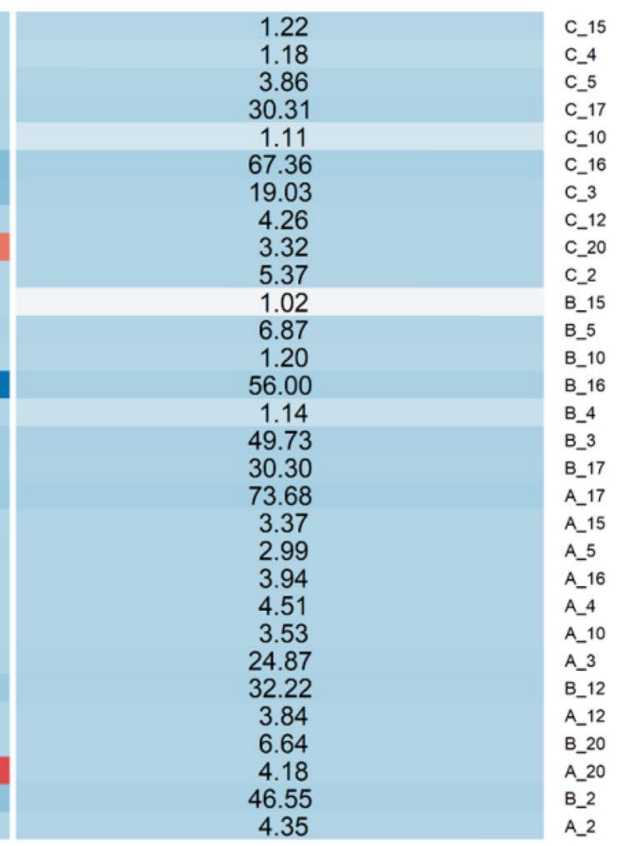

E. coli

Figure 7. Uptake of TBO for E. coli and S. epidermidis comparted to pure TBO when exposed to different TBO-PBAEs end-capped with (a) e1 and (b) e2.

\section{Discussion}

aPDT has numerous benefits as potential alternative to antibiotics for the treatment of infections such as skin and tissues that can be accessed with light sources ${ }^{10,12,42}$; however a critical drawback is the still relative long treatment time required (in the order of tens of minutes) that impacts the largescale application of this technology ${ }^{26}$. The design of novel and more efficient photosensitisers is generally accompanied by elevated drug costs; similarly, the use of drug delivery systems brings additional costs that must be offset by the enhanced efficacy. We have 


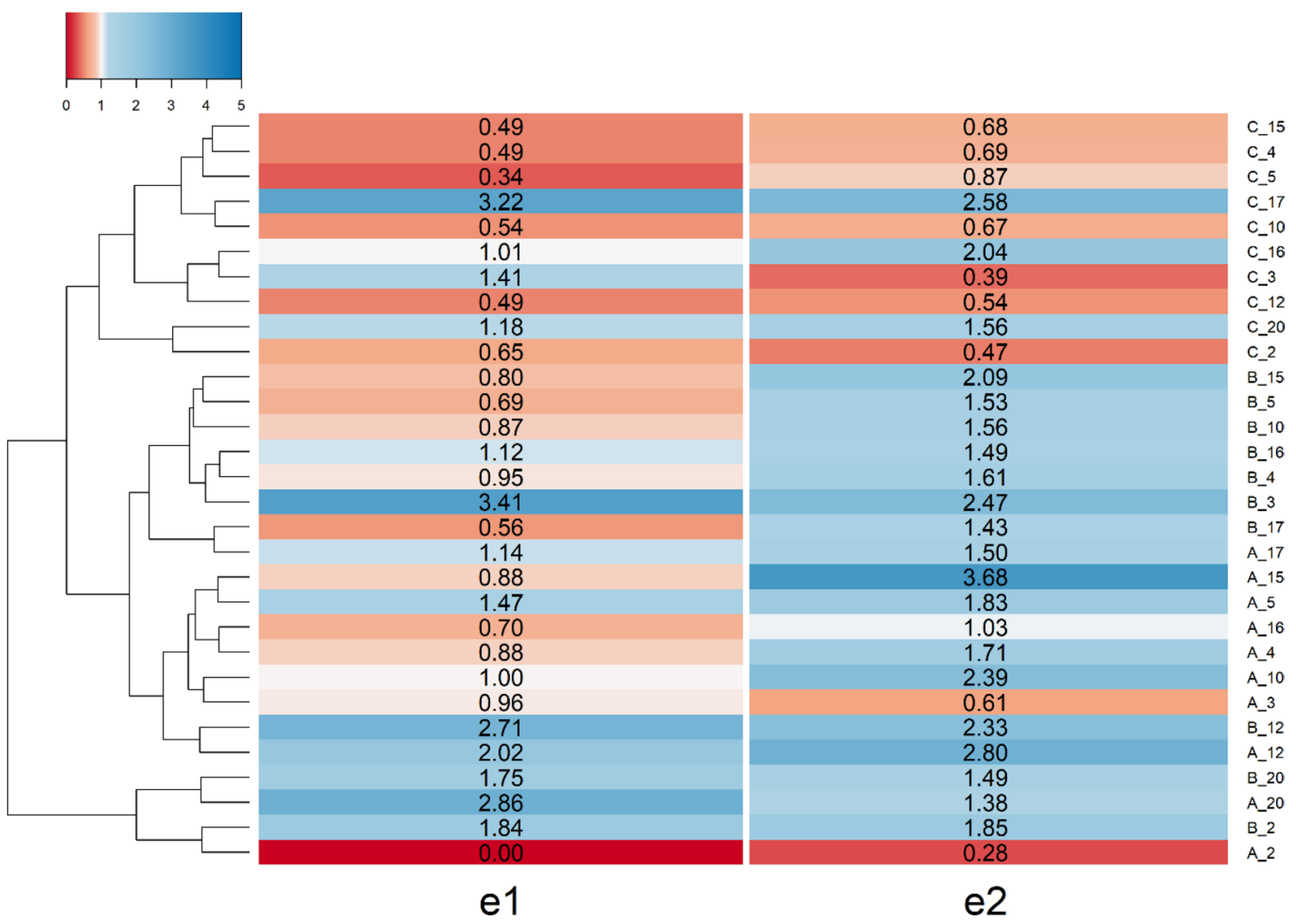

Figure 8. ROS produced by different PBAEs-TBO after $1 \mathrm{~min}$ irradiation compared to pure TBO.

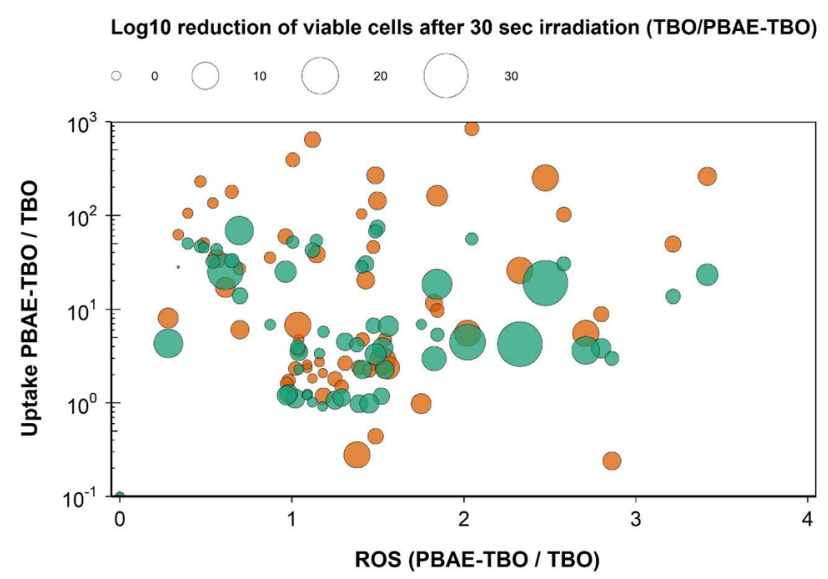

Figure 9. Correlation of ROS produced and TBO uptake on antimicrobial activity (ratio of log 10 reduction after 30 s laser irradiation in the presence of TBO or PBAE-TBO) of $E$. coli (green circles) and S. epidermidis (orange circles) by different PBAEs-TBO.

brought a new approach to boost aPDT efficacy through the use of polymers enhancing intracellular drug uptake; our starting point was the use of a photosensitiser commercially available and approved for use in humans, specifically TBO (widely used, inexpensive and with a very well-known safety profile) ${ }^{43}$, and polymers proven biocompatible and low cost such as PBAE. The safety profile of the compounds used in this technology offers both a shorter route to market and a high likelihood of future in vivo trials of this approach to prove safety while the use of low-cost chemicals also improves opportunities to be cost-effective.

We firstly validated the hypothesis of using PBAE to augment PDT on a variety of pathogens representing those most commonly encountered in SSTI ${ }^{44,45}$; subsequently the role of polymer backbone constituents was assessed through a broad library of PBAE and a new discovery, the impact on ROS, beside TBO uptake was also observed. PBAE features critical in this newly noticed phenomenon were assessed through PLS, one of chemometrics data analytic techniques that have been employed in drug design and analytical chemistry ${ }^{34,46,47}$, 
(a)

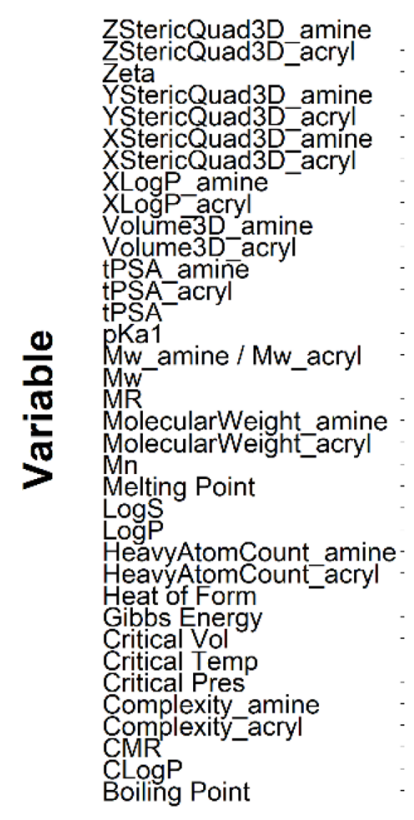

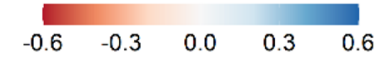

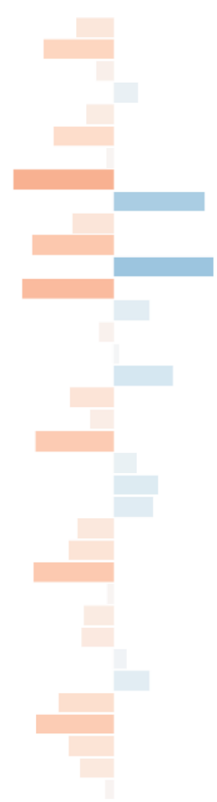

(b)

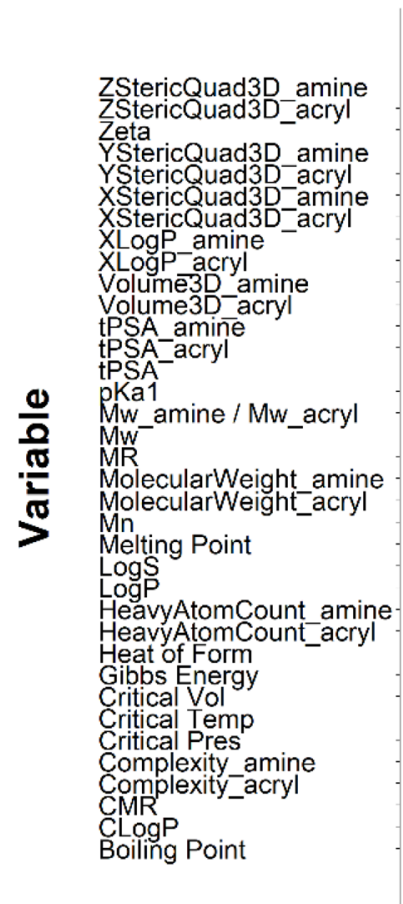

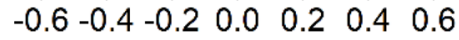

Correlation
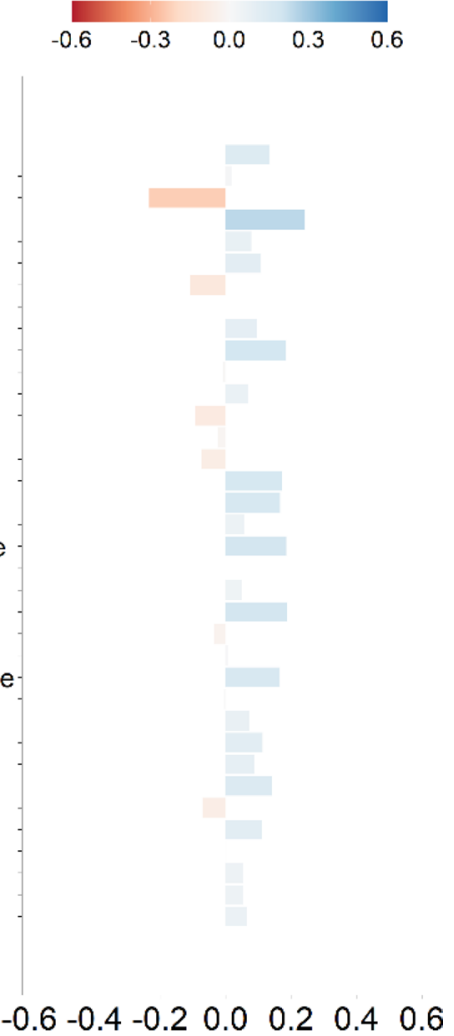

Correlation

Figure 10. PLS derived correlations for the different PBAEs characteristic (input parameters within the model) and ROS production for PBAE end-capped with e1 (a) and e2 (b).

(a)

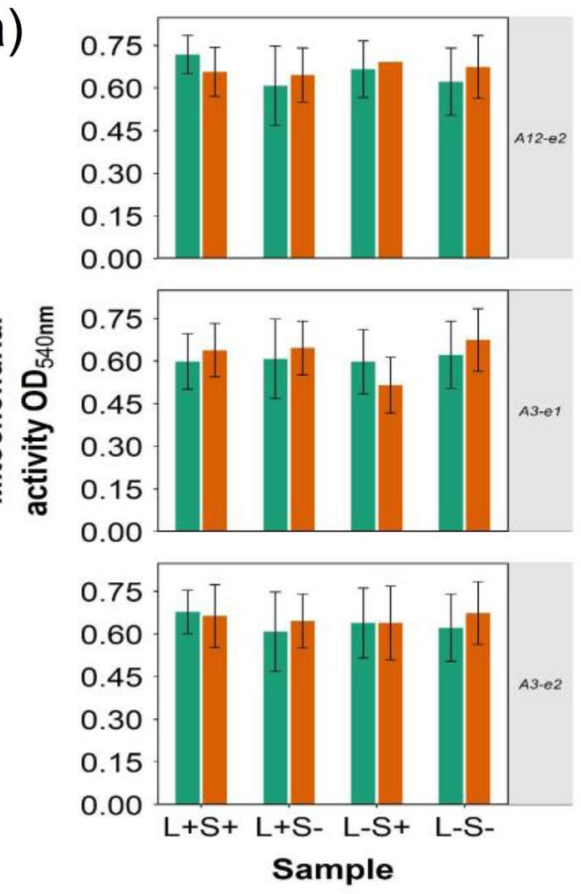

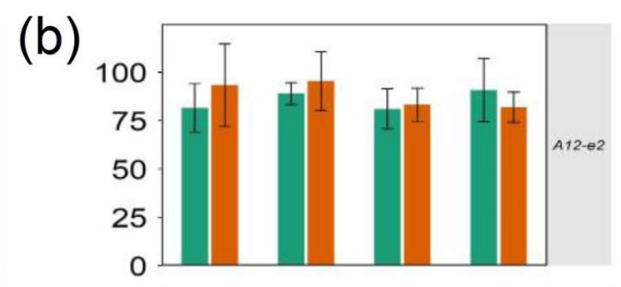
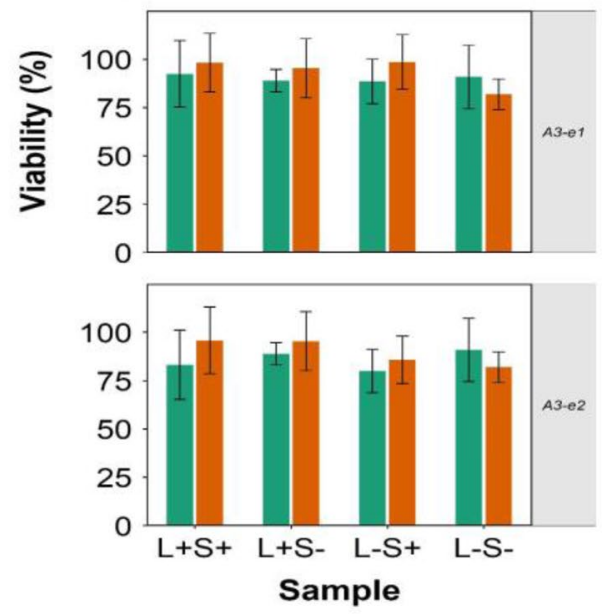

Figure 11. MTT and LDH on keratinocytes (green circles) and fibroblasts (orange circles) exposed to TBO and TBO-PBAEs (mean $\pm S D, n=3$ ). 
to also elicit possible mechanism. Initial in-vitro tests on keratinocytes cells and fibroblasts were also carried out exposing the cells to a selection of the PBAE-TBO complexes that exhibited the greatest enhancement of antimicrobial activity; in order to gather more robust safety data, two independent assays (MTT and LDH) were utilised with both showing the safety of the complexes PBAE-TBO on skin tissue cells.

The higher vulnerability of Gram+ over Gram- observed in this study (Fig. 5) was expected in line with several studies ${ }^{48-50}$ and is widely considered to be explained by the relatively porous layer of peptidoglycan and lipoteichoic acid constituting the cell wall of Gram + that allows the photosensitiser to cross the cell wall compared to the cell envelope of Gram- bacteria that exhibit higher resistance to photosensitiser uptake ${ }^{48}$.

PBAE were first described as gene transfer vectors ${ }^{32}$; subsequent evidence has validated such properties and identified key features and optimised the polymer chain backbone in order to maximise the opportunities offered by such polymers to transfer genes into target cells ${ }^{35,51}$. Further applications of PBAEs have been proposed for cancer drug delivery ${ }^{52-55}$, in layer-by-layer deposition of drug releasing coatings ${ }^{41,56-61}$ and drug localisation in cartilage ${ }^{33,34}$; currently no application of these polymers in antimicrobial technologies has been reported. Depending on the application, different PBAE features have been shown to pivot the outcome; for example PBAEs belonging to the family of B3 and A16 are known cell uptake enhancer in DNA delivery ${ }^{32,35,51}$ while A5 and $\mathrm{B} 5$ are better at driving drug uptake into cartilage ${ }^{34}$; additionally it has also been proven that end-capping has a further critical role ${ }^{34,35}$. Because of the essential role on TBO uptake into bacterial cells in controlling aPDT effect, it was not unexpected that polymer synthesised with acrylates such as A and B with amines such as 3 and 16 had the greatest impact on TBO uptake (Fig. 7).

All three constituents of PBAEs, namely diacrylate, amine and end-capping, influence all the outcomes investigated here (Figs. $6,7,8$ ) in agreement with previous results on the various applications of PBAEs ${ }^{34,35}$. None of the tested PBAEs have antimicrobial activity when used alone; furthermore, the overall performance of PBAE-TBO in bacteria inactivation is the combination of two phenomena in which PBAEs are responsible (Fig. 9), one is the cell uptake and another, seen for the first time in this work, in the generation of ROS by an irradiated photosensitisers. Because of the high reactivity of the singlet state, most of the energy absorbed by PS is re-emitted without resulting in any ROS. As PBAEs do not exhibit photosensitiser properties as shown by the absence of ROS for pure PBAE irradiated and the UV spectra of TBO is unaffected by the complexation with PBAE (Fig. 4), in order to explain the increase ROS formation, we hypothesised that PBAE may impact the stability of the TBO single/triple states resulting in a more efficient conversion of the light energy into ROS instead of re-emission; this charge separation and recombination phenomenon would be similar to those observed in polymers capped with light absorbing moieties ${ }^{62}$. Alternatively, PBAE may also interact in the mechanisms PS releases the absorbed energy from the light resulting in the formation of PBAE radicals with longer half-life that react with the bacterial cells wall causing the microorganism inactivation. The results of the PLS indicating that PBAE zeta potential is inversely correlated to the ROS production suggests that the electrostatic attraction between PBAE and TBO (positively charged) is necessary for the augmented ROS formation by TBO when in presence of PBAEs. Moreover, the high correlation between TSPA (the level of polar surface) characteristics of PBAE components further support this hypothesis; under this hypothesis, it was expected that the correlation between TPSA of acrylates and amine had opposite signs as amine have positive charges whilst acrylates only exhibit oxygen atoms that results in negative charges.

PBAEs are biodegradable, therefore, it is expected that storage of aqueous suspensions of PBAE-TBO would exhibit progressively diminishing improvements on aPDT. This obstacle could easily be overcome as we envisage the storage of the prepared PBAE-TBO dried in airtight containers with PBS added just before use.

The duration of the exposure time necessary to reach satisfactory antimicrobial effects is key in controlling the number of patients that can be treated given the available beds/treatment bays capacity; thus, increasing inactivation rates and, consequently, shortening treatment times, reduces the indirect costs of the treatment or the required investments to set-up facilities with a set turn-over of patients. Most of the technologies developed to enhance photosensitiser uptake rely on the conjugation of the light activated compound to a bacterial targeting polymer ${ }^{63}$, antimicrobial polypeptides ${ }^{64-66}$ or a bacterial wall disruption agent (i.e. gentamicin ${ }^{67}$ or vancomycin $\left.{ }^{68-70}\right)$. Another type of approach is the encapsulation of the photosensitiser in liposomes or micelle that drive the light activate compound inside the bacterial cell ${ }^{28,71,72}$. Compared to these approaches, the simple use of PBAE complexation with TBO that we developed removes the need of the conjugation or the encapsulation step thus reducing costs and maximising yield.

\section{Conclusions}

Antimicrobial PDT has the potential to replace antibiotics in the treatment of skin and tissue infections helping the fight against antibiotic resistance; current applications are still significantly restricted by long exposure time necessary.

We developed a new approach to improving aPDT efficacy thought the use of PBAE to improve bacterial uptake of photosensitisers resulting in shorter exposure times that, in turn, men higher treatment bays turnover. Reducing treatment times means that more patients can be treated with the currently available resources maximising their return. Further benefits of this technology over the current treatments of chronic wounds including the use of Iodine (Povidone), $\mathrm{KMnO}_{4}$, bleach or silver are the safety, low cost and biological tolerance (linked to the biological compatibility of the degradation products). Additionally, our technology has the advantage that the PBAE-TBO is already a gel and such its topical application is very easy and does not require further formulation into a gel. 
Received: 13 January 2021; Accepted: 17 March 2021

Published online: 31 March 2021

\section{References}

1. Kaye, K. S., Petty, L. A., Shorr, A. F. \& Zilberberg, M. D. Current epidemiology, etiology, and burden of acute skin infections in the United States. Clin. Infect. Dis. 68, S193-s199. https://doi.org/10.1093/cid/ciz002 (2019).

2. Ki, V. \& Rotstein, C. Bacterial skin and soft tissue infections in adults: A review of their epidemiology, pathogenesis, diagnosis, treatment and site of care. Can. J. Infect. Dis. Med. Microbiol. 19, 173-184. https://doi.org/10.1155/2008/846453 (2008).

3. Kaye, K. S. et al. Rising United States hospital admissions for acute bacterial skin and skin structure infections: Recent trends and economic impact. PLoS ONE 10, e0143276. https://doi.org/10.1371/journal.pone.0143276 (2015).

4. Suaya, J. A. et al. Incidence and cost of hospitalizations associated with Staphylococcusaureus skin and soft tissue infections in the United States from 2001 through 2009. BMC Infect. Dis. 14, 296. https://doi.org/10.1186/1471-2334-14-296 (2014).

5. Frei, C. R., Makos, B. R., Daniels, K. R. \& Oramasionwu, C. U. Emergence of community-acquired methicillin-resistant Staphylococcusaureus skin and soft tissue infections as a common cause of hospitalization in United States children. J. Pediatr. Surg. 45, 1967-1974. https://doi.org/10.1016/j.jpedsurg.2010.05.009 (2010).

6. Lee, G. C., Boyd, N. K., Lawson, K. A. \& Frei, C. R. Incidence and cost of skin and soft tissue infections in the United States. Value Health 18, A245. https://doi.org/10.1016/j.jval.2015.03.1424 (2015).

7. Estrada, S., Lodise, T. P., Tillotson, G. S. \& Delaportas, D. The real-world economic and clinical management of adult patients with skin and soft tissue infections (SSTIs) with oritavancin: Data from two multicenter observational cohort studies. Drugs Real World Outcomes 7, 6-12. https://doi.org/10.1007/s40801-020-00199-3 (2020).

8. Corey, G. R., McKinnell, J. A. \& Rybak, M. J. Delafloxacin in acute bacterial skin and skin structure infections. Clin. Infect. Dis. 68, S191-S192. https://doi.org/10.1093/cid/ciy1089 (2019).

9. Dougherty, T. J. et al. Photodynamic therapy. J. Natl. Cancer Inst. 90, 889-905. https://doi.org/10.1093/jnci/90.12.889 (1998).

10. Plotino, G., Grande, N. M. \& Mercade, M. Photodynamic therapy in endodontics. Int. Endod. J. 52, 760-774. https://doi.org/10. 1111/iej.13057 (2019).

11. Martinelli, N., Curci, V., Quarantiello, A. \& Saldalamacchia, G. The benefits of antimicrobial photodynamic therapy with RLP068 in the management of diabetic foot ulcers. Drugs Context 8, 212610. https://doi.org/10.7573/dic.212610 (2019).

12. Brocco, E. et al. Photodynamic topical antimicrobial therapy for infected diabetic foot ulcers in patients with diabetes: A case series. Int. J. Lower Extrem. Wounds 1, 1. https://doi.org/10.1177/1534734620929889 (2020).

13. Perni, S., Prokopovich, P., Pratten, J., Parkin, I. P. \& Wilson, M. Nanoparticles: Their potential use in antibacterial photodynamic therapy. Photochem. Photobiol. Sci. 10, 712-720. https://doi.org/10.1039/c0pp00360c (2011).

14. Wainwright, M. et al. Photoantimicrobials-Are we afraid of the light?. Lancet Infect. Dis 17, e49-e55. https://doi.org/10.1016/ S1473-3099(16)30268-7 (2017).

15. Verebová, V., Beneš, J. \& Staničová, J. Biophysical characterization and anticancer activities of photosensitive phytoanthraquinones represented by hypericin and its model compounds. Molecules 25, 5666. https://doi.org/10.3390/molecules25235666 (2020).

16. Zeina, B., Greenman, J., Corry, D. \& Purcell, W. M. Cytotoxic effects of antimicrobial photodynamic therapy on keratinocytes in vitro. Br. J. Dermatol. 146, 568-573. https://doi.org/10.1046/j.1365-2133.2002.04623.x (2002).

17. Zeina, B., Greenman, J., Corry, D. \& Purcell, W. M. Antimicrobial photodynamic therapy: Assessment of genotoxic effects on keratinocytes in vitro. Br. J. Dermatol. 148, 229-232. https://doi.org/10.1046/j.1365-2133.2003.05091.x (2003).

18. Giuliani, F. et al. In vitro resistance selection studies of RLP068/Cl, a new $\mathrm{Zn}$ (II) phthalocyanine suitable for antimicrobial photodynamic therapy. Antimicrob. Agents Chemother. 54, 637-642. https://doi.org/10.1128/aac.00603-09 (2010).

19. Tavares, A. et al. Antimicrobial photodynamic therapy: study of bacterial recovery viability and potential development of resistance after treatment. Mar. Drugs 8, 91-105 (2010).

20. Maisch, T. Resistance in antimicrobial photodynamic inactivation of bacteria. Photochem. Photobiol. Sci. 14, 1518-1526. https:// doi.org/10.1039/C5PP00037H (2015).

21. Tubby, S., Wilson, M. \& Nair, S. P. Inactivation of staphylococcal virulence factors using a light-activated antimicrobial agent. $B M C$ Microbiol. 9, 211. https://doi.org/10.1186/1471-2180-9-211 (2009).

22. ClinicalTrials.gov. Photodisinfection for the decolonization of Staphylococcus aureus in hemodialysis patients. https://ClinicalTr ials.gov/show/NCT02741869

23. ClinicalTrials.gov. A small clinical study: photodynamic therapy to treat hidradenitis suppurativa. https://ClinicalTrials.gov/show/ NCT00395187

24. ClinicalTrials.gov. A double blinded, prospective, randomized, vehicle controlled multi-center study of photodynamic therapy with Visonac cream in patients with Acne vulgaris. https://ClinicalTrials.gov/show/NCT01347879

25. ClinicalTrials.gov. Efficacy and safety of painless 5-aminolevulinic acid photodynamic therapy for moderate and severe Acne vulgaris. https://ClinicalTrials.gov/show/NCT04167982

26. NHS. Photodynamic therapy (PDT). https://www.nhs.uk/conditions/photodynamic-therapy/\#: :text=It\%20usually\%20takes\% 20around\%202,how\%20big\%20the\%20area\%20is (2019).

27. Nakonechny, F., Firer, M. A., Nitzan, Y. \& Nisnevitch, M. Intracellular antimicrobial photodynamic therapy: A novel technique for efficient eradication of pathogenic bacteria. Photochem. Photobiol. 86, 1350-1355. https://doi.org/10.1111/j.1751-1097.2010. 00804.x (2010).

28. Boccalini, G. et al. Methylene blue-containing liposomes as new photodynamic anti-bacterial agents. J. Mater. Chem. B 5, 27882797. https://doi.org/10.1039/C6TB03367A (2017).

29. Hamblin, M. R., Miller, J. L., Rizvi, I. \& Ortel, B. Degree of substitution of chlorin e6 on charged poly-L-lysine chains affects their cellular uptake, localization and phototoxicity towards macrophages and cancer cells. J. Xray Sci. Technol. 10, 139-152 (2002).

30. Sperandio, F. F., Huang, Y. Y. \& Hamblin, M. R. Antimicrobial photodynamic therapy to kill Gram-negative bacteria. Recent Pat. Anti-Infect. Drug Discov. 8, 108-120. https://doi.org/10.2174/1574891x113089990012 (2013).

31. Masiera, N. et al. Antimicrobial photodynamic therapy by means of porphycene photosensitizers. J. Photochem. Photobiol. B Biol. 174, 84-89. https://doi.org/10.1016/j.jphotobiol.2017.07.016 (2017).

32. Lynn, D. M. \& Langer, R. Degradable poly( $\beta$-amino esters): Synthesis, characterization, and self-assembly with plasmid DNA. J. Am. Chem. Soc. 122, 10761-10768. https://doi.org/10.1021/ja0015388 (2000).

33. Perni, S. \& Prokopovich, P. Poly-beta-amino-esters nano-vehicles based drug delivery system for cartilage. Nanomed. Nanotechnol. Biol. Med. 13, 539-548. https://doi.org/10.1016/j.nano.2016.10.001 (2017).

34. Perni, S. \& Prokopovich, P. Optimisation and feature selection of poly-beta-amino-ester as a drug delivery system for cartilage. J. Mater. Chem. B 8, 5096-5108. https://doi.org/10.1039/c9tb02778e (2020).

35. Green, J. J., Langer, R. \& Anderson, D. G. A combinatorial polymer library approach yields insight into nonviral gene delivery. Acc. Chem. Res. 41, 749-759. https://doi.org/10.1021/ar7002336 (2008).

36. R Core Team. R: A Language and Environment for Statistical Computing (R Foundation for Statistical Computing, 2019).

37. Sanchez, G. plsdepot: Partial Least Squares (PLS) Data Analysis Methods. R package version 0.1.17 (2012).

38. Johnson, E. E., Mueller, H. G. \& Ricketts, T. A. Statistically derived factors of varied importance to audiologists when making a hearing aid brand preference decision. J. Am. Acad. Audiol. 20, 40-48 (2009). 
39. Bown, H. K. et al. In vitro model for predicting bioavailability of subcutaneously injected monoclonal antibodies. J. Control. Release 273, 13-20. https://doi.org/10.1016/j.jconrel.2018.01.015 (2018).

40. Wall, I. B. et al. Fibroblast dysfunction is a key factor in the non-healing of chronic venous leg ulcers. J. Investig. Dermatol. 128, 2526-2540. https://doi.org/10.1038/jid.2008.114 (2008).

41. Rivera, M. C., Perni, S., Sloan, A. \& Prokopovich, P. Anti-inflammatory drug-eluting implant model system to prevent wear particle-induced periprosthetic osteolysis. Int. J. Nanomed. 14, 1069-1084. https://doi.org/10.2147/ijn.S188193 (2019).

42. Cieplik, F. et al. Antimicrobial photodynamic therapy-What we know and what we don't. Crit. Rev. Microbiol. 44, 571-589. https:// doi.org/10.1080/1040841X.2018.1467876 (2018).

43. Sridharan, G. \& Shankar, A. A. Toluidine blue: A review of its chemistry and clinical utility. J. Oral Maxillofac. Pathol. 16, 251-255. https://doi.org/10.4103/0973-029X.99081 (2012).

44. Lipsky, B. A. et al. Inappropriate initial antibiotic treatment for complicated skin and soft tissue infections in hospitalized patients: Incidence and associated factors. Diagn. Microbiol. Infect. Dis. 79, 273-279. https://doi.org/10.1016/j.diagmicrobio.2014.02.011 (2014).

45. Ray, G. T., Suaya, J. A. \& Baxter, R. Incidence, microbiology, and patient characteristics of skin and soft-tissue infections in a U.S. population: A retrospective population-based study. BMC Infect. Dis. 13, 252. https://doi.org/10.1186/1471-2334-13-252 (2013).

46. Chong, J., Wishart, D. S. \& Xia, J. Using MetaboAnalyst 4.0 for comprehensive and integrative metabolomics data analysis. Curr. Protoc. Bioinform. 68, e86. https://doi.org/10.1002/cpbi.86 (2019).

47. Aminu, M. \& Ahmad, N. A. Complex chemical data classification and discrimination using locality preserving partial least squares discriminant analysis. ACS Omega 5, 26601-26610. https://doi.org/10.1021/acsomega.0c03362 (2020).

48. Hamblin, M. R. \& Hasan, T. Photodynamic therapy: A new antimicrobial approach to infectious disease?. Photochem. Photobiol. Sci. 3, 436-450. https://doi.org/10.1039/b311900a (2004).

49. Soliman, N., Sol, V., Ouk, T. S., Thomas, C. M. \& Gasser, G. Encapsulation of a Ru(II) polypyridyl complex into polylactide nanoparticles for antimicrobial photodynamic therapy. Pharmaceutics https://doi.org/10.3390/pharmaceutics12100961 (2020).

50. Perni, S., Drexler, S., Ruppel, S. \& Prokopovich, P. Lethal photosensitisation of bacteria using silica-TBO nanoconjugates. Colloids Surf. A 510, 293-299. https://doi.org/10.1016/j.colsurfa.2016.06.022 (2016).

51. Little, S. R. et al. Poly- $\beta$ amino ester-containing microparticles enhance the activity of nonviral genetic vaccines. Proc. Natl. Acad. Sci. 101, 9534-9539. https://doi.org/10.1073/pnas.0403549101\%JProceedingsoftheNationalAcademyofSciencesoftheUnitedStateso fAmerica (2004).

52. Kim, J. et al. Verteporfin-loaded poly(ethylene glycol)-poly(beta-amino ester)-poly(ethylene glycol) triblock micelles for cancer therapy. Biomacromol 19, 3361-3370. https://doi.org/10.1021/acs.biomac.8b00640 (2018).

53. Wilson, D. R. et al. Biodegradable STING agonist nanoparticles for enhanced cancer immunotherapy. Nanomed. Nanotechnol. Biol. Med. 14, 237-246. https://doi.org/10.1016/j.nano.2017.10.013 (2018).

54. Yang, C. et al. Delivery of anticancer drug using pH-sensitive micelles from triblock copolymer MPEG-b-PBAE-b-PLA. Mater. Sci. Eng. C Mater. Biol. Appl. 84, 254-262. https://doi.org/10.1016/j.msec.2017.12.003 (2018).

55. Mastorakos, P. et al. Biodegradable brain-penetrating DNA nanocomplexes and their use to treat malignant brain tumors. J. Control. Release 262, 37-46. https://doi.org/10.1016/j.jconrel.2017.07.009 (2017).

56. DeMuth, P. C., Moon, J. J., Suh, H., Hammond, P. T. \& Irvine, D. J. Releasable layer-by-layer assembly of stabilized lipid nanocapsules on microneedles for enhanced transcutaneous vaccine delivery. ACS Nano 6, 8041-8051. https://doi.org/10.1021/nn302639r (2012).

57. Wood, K. C., Boedicker, J. Q., Lynn, D. M. \& Hammond, P. T. Tunable drug release from hydrolytically degradable layer-by-layer thin films. Langmuir 21, 1603-1609. https://doi.org/10.1021/la0476480 (2005).

58. Wood, K. C., Chuang, H. F., Batten, R. D., Lynn, D. M. \& Hammond, P. T. Controlling interlayer diffusion to achieve sustained, multiagent delivery from layer-by-layer thin films. Proc. Natl. Acad. Sci. U.S.A. 103, 10207-10212. https://doi.org/10.1073/pnas. 0602884103 (2006).

59. Al Thaher, Y., Latanza, S., Perni, S. \& Prokopovich, P. Role of poly-beta-amino-esters hydrolysis and electrostatic attraction in gentamicin release from layer-by-layer coatings. J. Colloid Interface Sci. 526, 35-42. https://doi.org/10.1016/j.jcis.2018.04.042 (2018).

60. Al Thaher, Y., Yang, L., Jones, S. A., Perni, S. \& Prokopovich, P. LbL-assembled gentamicin delivery system for PMMA bone cements to prolong antimicrobial activity. PLoS ONE 13, e0207753. https://doi.org/10.1371/journal.pone.0207753 (2018).

61. Perni, S. et al. Long acting anti-infection constructs on titanium. J. Control. Release 326, 91-105. https://doi.org/10.1016/j.jconr el.2020.06.013 (2020).

62. Karsten, B. P., Bouwer, R. K., Hummelen, J. C., Williams, R. M. \& Janssen, R. A. Charge separation and (triplet) recombination in diketopyrrolopyrrole-fullerene triads. Photochem. Photobiol. Sci. 9, 1055-1065. https://doi.org/10.1039/c0pp00098a (2010).

63. Zhang, A.-N. et al. A versatile bacterial membrane-binding chimeric peptide with enhanced photodynamic antimicrobial activity. J. Mater. Chem. B 7, 1087-1095. https://doi.org/10.1039/C8TB03094D (2019).

64. Johnson, G. A., Muthukrishnan, N. \& Pellois, J.-P. Photoinactivation of Gram positive and Gram negative bacteria with the antimicrobial peptide (KLAKLAK)2 conjugated to the hydrophilic photosensitizer eosin Y. Bioconjug. Chem. 24, 114-123. https:// doi.org/10.1021/bc3005254 (2013).

65. Dosselli, R. et al. Synthesis, characterization, and photoinduced antibacterial activity of porphyrin-type photosensitizers conjugated to the antimicrobial peptide apidaecin 1b. J. Med. Chem. 56, 1052-1063. https://doi.org/10.1021/jm301509n (2013).

66. de Freitas, L. M. et al. Antimicrobial photodynamic therapy enhanced by the peptide aurein 1.2. Sci. Rep. 8, 4212. https://doi.org/ 10.1038/s41598-018-22687-x (2018).

67. Nieves, I., Hally, C., Viappiani, C., Agut, M. \& Nonell, S. A porphycene-gentamicin conjugate for enhanced photodynamic inactivation of bacteria. Bioorg. Chem. 97, 103661. https://doi.org/10.1016/j.bioorg.2020.103661 (2020).

68. Xing, B. et al. Multifunctional divalent vancomycin: The fluorescent imaging and photodynamic antimicrobial properties for drug resistant bacteria. Chem. Commun. 47, 1601-1603. https://doi.org/10.1039/C0CC04434B (2011).

69. Choi, K.-H. et al. Photosensitizer and vancomycin-conjugated novel multifunctional magnetic particles as photoinactivation agents for selective killing of pathogenic bacteria. Chem. Commun. 48, 4591-4593. https://doi.org/10.1039/C2CC17766H (2012).

70. Huang, L. et al. Progressive cationic functionalization of chlorin derivatives for antimicrobial photodynamic inactivation and related vancomycin conjugates. Photochem. Photobiol. Sci. 17, 638-651. https://doi.org/10.1039/C7PP00389G (2018).

71. Tsai, T., Yang, Y.-T., Wang, T.-H., Chien, H.-F. \& Chen, C.-T. Improved photodynamic inactivation of gram-positive bacteria using hematoporphyrin encapsulated in liposomes and micelles. Lasers Surg. Med. 41, 316-322. https://doi.org/10.1002/lsm.20754 (2009).

72. Sharma, B., Kaur, G., Chaudhary, G. R., Gawali, S. L. \& Hassan, P. A. High antimicrobial photodynamic activity of photosensitizer encapsulated dual-functional metallocatanionic vesicles against drug-resistant bacteria S. aureus. Biomater. Sci. 8, 2905-2920. https://doi.org/10.1039/D0BM00323A (2020).

\section{Author contributions}

P.P. conceived the idea for the work. S.P. and P.P. wrote the main manuscript, S.P. and P.P. prepared the figures and carried out data analysis. E.P. contributed to experimental data collection. All authors reviewed the manuscript. 


\section{Competing interests}

PP and SP are named inventors in a patent application related to the technology described. ECP has no conflict to declare.

\section{Additional information}

Supplementary Information The online version contains supplementary material available at https://doi.org/ 10.1038/s41598-021-86773-3.

Correspondence and requests for materials should be addressed to P.P.

Reprints and permissions information is available at www.nature.com/reprints.

Publisher's note Springer Nature remains neutral with regard to jurisdictional claims in published maps and institutional affiliations.

(c) (i) Open Access This article is licensed under a Creative Commons Attribution 4.0 International License, which permits use, sharing, adaptation, distribution and reproduction in any medium or format, as long as you give appropriate credit to the original author(s) and the source, provide a link to the Creative Commons licence, and indicate if changes were made. The images or other third party material in this article are included in the article's Creative Commons licence, unless indicated otherwise in a credit line to the material. If material is not included in the article's Creative Commons licence and your intended use is not permitted by statutory regulation or exceeds the permitted use, you will need to obtain permission directly from the copyright holder. To view a copy of this licence, visit http://creativecommons.org/licenses/by/4.0/.

(C) The Author(s) 2021 